\title{
The use of endoscopic ultrasonography and other imaging modalities in the preoperative staging of rectal villous tumours: A case of overstaging by magnetic resonance imaging
}

\author{
Michelle Buresi MD PhD ${ }^{1 *}$, Iman Zandieh MD FRCPC ${ }^{1 *}$, Alexander G Nagy MD FRCSC ${ }^{2}$, \\ Audrey Spielmann MD FRCPC ${ }^{2}$, William C Yee MD FRCPC ${ }^{3}$, Alan A Weiss MD FRCPC ${ }^{1}$, Eric M Yoshida MD FRCPC
}

M Buresi, I Zandieh, AG Nagy, et al. The use of endoscopic ultrasonography and other imaging modalities in the preoperative staging of rectal villous tumours: A case of overstaging by magnetic resonance imaging. Can J Gastroenterol 2009; 23(9):639-641.

A case of a 60-year-old man with recurrent rectal villous adenoma is described. Preoperative staging with endoscopic ultrasound (EUS) and magnetic resonance imaging (MRI) revealed very discordant results. EUS showed a tumour present in the mucosa with no submucosal invasion, while MRI revealed invasion of the muscularis propria consistent with an invasive stage T2 carcinoma. Based on the MRI findings, the patient underwent a low anterior resection of the tumour. The surgical pathology specimen revealed a villous adenoma with lowgrade dysplasia but no carcinoma and no extension into the muscularis propria. The present case highlights the uncertainty that currently exists as to which imaging modality provides the greatest accuracy in the staging of rectal cancer and in guiding the type of surgical procedure performed. Two recent meta-analyses and a systematic review of the literature point to EUS as the imaging modality of choice for determining muscularis propria and perirectal tissue invasion, as well as nodal involvement.

Key Words: Endoscopic ultrasound; MRI; Rectal cancer; Staging

\section{CASE PRESENTATION}

A 60-year-old man who underwent colonoscopy was found to have a $2 \mathrm{~cm}$ sessile polyp that was located $10 \mathrm{~cm}$ from the anal verge and successfully removed. The polyp was a tubulovillous adenoma with focal high-grade dysplasia. A flexible sigmoidoscopy performed three months later, as well as a repeat colonoscopy one year after the initial colonoscopy, were both negative for recurrence.

A colonoscopy performed three years after the initial colonoscopy revealed a sessile polyp, $3 \mathrm{~cm}$ in size, at $10 \mathrm{~cm}$ from the anal verge. Biopsies were taken and reported to be fragments of a villous adenoma with low-grade dysplasia. Due to the previous high-grade dysplasia, relatively rapid recurrence and concern that a cancer may have been missed by sampling error, a pelvic magnetic resonance imaging (MRI) scan and an endoscopic ultrasound (EUS) were performed before definitive excision. The MRI revealed an invasive rectal mass involving the muscularis propria but without breach of the adventitia, consistent with a T2 rectal carcinoma (Figure 1). No pelvic lymphadenopathy was detected. The EUS revealed a rectal mass involving the mucosa and submucosa, with no involvement of the mus-
L'utilisation de l'endoscopie et d'autres modalités d'imagerie dans la classification préopératoire de tumeurs villeuses rectales : Un cas de surclassification par imagerie par résonance magnétique

Le cas d'un homme de 60 ans atteint d'un adénome villeux rectal est présenté. La classification préopératoire par endoscopie (ES) et l'imagerie par résonance magnétique (IRM) ont donné des résultats très incompatibles. L'ES a révélé une tumeur de la muqueuse sans invasion de la sousmuqueuse, tandis que l'IRM a révélé une invasion de la couche externe évocatrice d'un carcinome envahissant de stade T2. Compte tenu des résultats de l'IRM, le patient a subi une résection antérieure basse de la tumeur. L'échantillon pathologique chirurgical a donné un résultat d'adénome villeux avec dysplasie bénigne, sans carcinome et sans empiétement dans la couche externe. Le présent cas fait ressortir l'incertitude actuelle quant à la modalité d'imagerie la plus précise pour classifier le cancer rectal et orienter le type d'intervention chirurgicale à privilégier. Deux récentes méta-analyses et analyses bibliographiques systématiques laissent penser que l'ES est la modalité d'imagerie de choix pour déterminer une invasion de la couche externe et des tissus périrectaux, ainsi qu'une atteinte ganglionnaire.

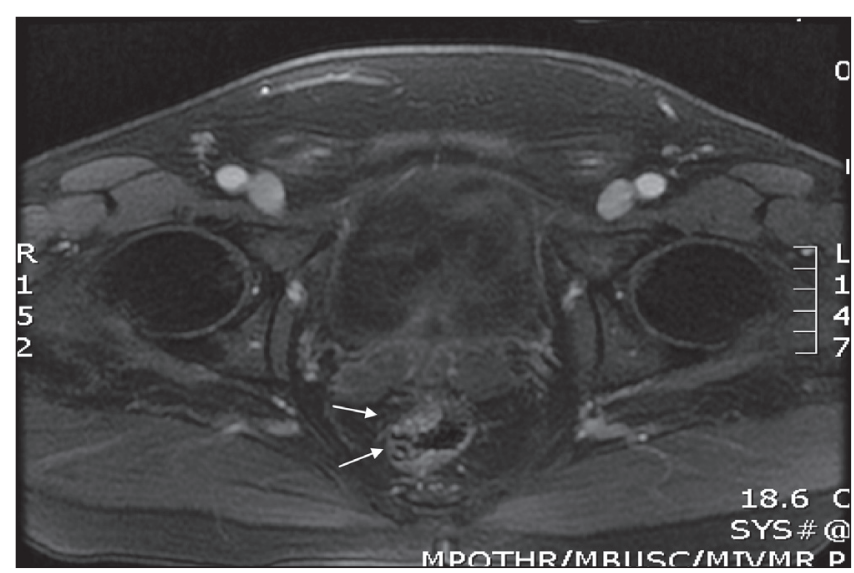

Figure 1) Postcontrast $T 1$ axial magnetic resonance image revealing the rectal lesion with invasion of the muscularis propria (white arrows) without breach of the adventitia, consistent with a $T 2$ rectal carcinoma

cularis propria (Figure 2). The results of the MRI and EUS, as well as the surgical versus endoscopic resection treatment

*Co-first authors; ${ }^{1}$ Department of Medicine; ${ }^{2}$ Department of Surgery; ${ }^{3}$ Department of Radiology, University of British Columbia,

Vancouver, British Columbia

Correspondence: Dr Eric M Yoshida, Division of Gastroenterology, Vancouver General Hospital, Diamond Health Care Centre, 5153-2775

Laurel Street, Vancouver, British Columbia V5Z 1M9. Telephone 604-875-5371, fax 604-875-5447, e-mail eric.yoshida@vch.ca

Received for publication June 1, 2008. Accepted September 25, 2008 


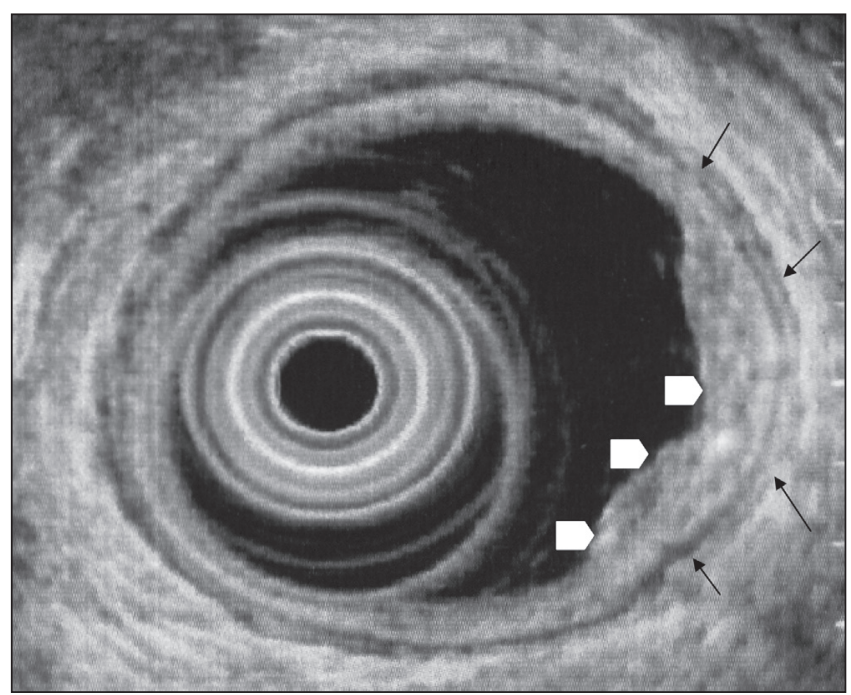

Figure 2) Endoscopic ultrasound image of the rectal lesion (white arrowheads) involving the mucosa and submucosa, with no invasion of the muscularis propria (black arrows)

options, were discussed with the patient, who opted for a surgical resection.

The patient underwent a low anterior resection and end-toend anastomosis with loop ileostomy. Pathology review of the resected rectosigmoid revealed a villous adenoma with lowgrade dyplasia. There was no evidence of muscularis propria invasion, and a total of five pericolic and two mesorectal lymph nodes were excised and deemed benign. The patient underwent ileostomy reversal five months later. He remains asymptomatic with no recurrence of tumours.

\section{DISCUSSION}

Rectal cancer is the third most common malignancy in the western world, and is the second most common cause of cancer deaths $(1,2)$. Surgical excision is the primary treatment modality and because local recurrence after resection is associated with a poor prognosis, much attention has been focused on determining the best diagnostic and treatment strategies to optimize local control of the primary tumour (3).

Surgical excision of rectal cancer consists of either transanal local excision, endoscopic microsurgery or total mesorectal excision. The stage of the tumour, based on the tumour, node, metastasis classification system (Table 1), impacts heavily on prognosis and determines the type of surgical procedure performed $(4,5)$. Transanal local excision or endoscopic microsurgery are considered for cancers staged at T1 or lower, while total mesorectal excision would be reserved for stages T2 and T3. Thus, accurate preoperative staging of rectal tumours is paramount in guiding the type of surgical procedure performed.

Computed tomography (CT), MRI and EUS have all been used to stage rectal tumours; however, controversy exists as to which diagnostic imaging modality provides the most accurate information. The diagnostic accuracy of these imaging techniques for assessing the depth of tumour invasion, spread to the mesorectal fascia and lymph node involvement has been compared extensively. The findings of the largest and most recent trials are discussed in the present article and are summarized in Table 2.
TABLE 1

Definitions in the American Joint Committee on Cancer
tumour, node, metastasis staging system for colorectal cancer

\begin{tabular}{ll}
\hline Category & Definition \\
\hline Tis & Carcinoma in situ; intraepithelial or \\
& intramucosal carcinoma \\
T1 & Tumour invades submucosa \\
T2 & Tumour invades muscularis propria \\
T3 & Tumour invades through the muscularis propria \\
& into the subserosa or into nonperitonealized \\
T4 & pericolic or perirectal tissues \\
Regional lymph nodes (N) & Tumour directly invades other organs or struc- \\
NX & tures and/or perforates visceral peritoneum \\
N0 & Regional nodes cannot be assessed \\
N1 & No regional nodal metastasis \\
N2 & Metastasis in one to three regional lymph \\
& nodes \\
Distant metastasis (M) & Metastasis in four or more regional lymph \\
MX & nodes \\
M0 & Distant metastasis cannot be assessed \\
\hline Nabistant metastasis
\end{tabular}

Table adapted from the American Joint Committee on Cancer Staging Manual, Sixth Edition (12)

A recent meta-analysis (6) found that EUS, when compared with MRI, overstaged muscularis propria invasion in T1 cancers, while CT and MRI each significantly understaged perirectal tissue invasion for tumours staged at T3 or greater. A second meta-analysis (7) found that EUS was also more effective at identifying nodal status than MRI and CT, although the finding was not statistically significant. Furthermore, only MRI was able to predict circumferential resection margins with accuracy.

Findings from other studies have contradicted these results. Kulinna et al (8) found that multislice CT was more sensitive and specific for delineating rectal wall invasion and perirectal lymph node spread than EUS. To add to the controversy, Chun et al (9) found that phased array 3 Tesla MRI and EUS were equally sensitive and specific for detecting invasion of the muscularis propria and lymph node involvement. However, there was evidence to suggest that EUS was more accurate at determining perirectal tissue invasion. Finally, a recent systematic review of the literature (10) found that EUS was more accurate than MRI at characterizing early localized rectal cancers while MRI was more useful in advanced disease because it provided a clearer definition of the mesorectum and fascia. The authors concluded that EUS and MRI have complementary roles in the assessment of tumour depth.

Taken together, the recent literature seems to indicate that EUS is the modality of choice for staging rectal cancer, although some limitations may exist. The advantages of this modality depend heavily on operator experience, and EUS may be less accurate than MRI in characterizing highly stenotic or proximal tumours and distant metastases (8). On the other hand, advances such as three-dimensional EUS may improve accuracy, and EUS-guided fine-needle aspiration of lymph nodes may further 
TABLE 2

Summary of findings of studies comparing diagnostic accuracy of endoscopic ultrasound (EUS), computed tomography (CT) and magnetic resonance imaging (MRI)

\begin{tabular}{|c|c|c|c|c|c|}
\hline Staging parameter & EUS & CT & MRI & $\mathbf{P}$ & Author (reference) \\
\hline \multirow{7}{*}{$\begin{array}{l}\text { Muscularis propria } \\
\text { invasion }\end{array}$} & Sensitivity $94 \%$ & & Sensitivity $94 \%$ & NS & Bipat et al (6) \\
\hline & Specificity $86 \%$ & & Specificity 69\% & 0.02 & \\
\hline & Sensitivity 59\% & Sensitivity $82 \%$ & & $<0.05$ & Kulinna et al (8) \\
\hline & Specificity 63\% & Specificity $84 \%$ & & $<0.05$ & \\
\hline & Sensitivity $100 \%$ & & Sensitivity $100 \%$ & NS & Chun et al (9) \\
\hline & Specificity 61\% & & Specificity $67 \%$ & NS & \\
\hline & Accuracy $82 \%$ & & Accuracy $76 \%$ & & Skandarajah and Tjandra (10) \\
\hline \multirow[t]{5}{*}{ Perirectal tissue invasion } & Sensitivity $90 \%$ & Sensitivity $79 \%$ & Sensitivity $82 \%$ & 0.001 (EUS/CT) & Bipat et al (6) \\
\hline & Specificity $75 \%$ & Specificity 78\% & Specificity $76 \%$ & 0.003 (EUS/MRI) & \\
\hline & Sensitivity $100 \%$ & & Sensitivity $91 \%$ & NS & Chun et al (9) \\
\hline & Specificity $82 \%$ & & Specificity 93\% & NS & \\
\hline & Accuracy 0.996 & & Accuracy 0.938 & 0.028 & \\
\hline \multirow[t]{2}{*}{ Adjacent organ invasion } & Sensitivity $70 \%$ & Sensitivity $72 \%$ & Sensitivity $74 \%$ & NS & Bipat et al (6) \\
\hline & Specificity $97 \%$ & Specificity 96\% & Specificity 96\% & NS & \\
\hline \multirow[t]{7}{*}{ Lymph node involvement } & Sensitivity $67 \%$ & Sensitivity $55 \%$ & Sensitivity $66 \%$ & NS & Bipat et al (6) \\
\hline & Specificity 78\% & Specificity $74 \%$ & Specificity $76 \%$ & NS & \\
\hline & Sensitivity 55\% & Sensitivity $75 \%$ & & $<0.05$ & Kulinna et al (8) \\
\hline & Specificity $71 \%$ & Specificity 85\% & & NS & \\
\hline & Sensitivity 58\% & & Sensitivity $64 \%$ & NS & Chun et al (9) \\
\hline & Specificity $82 \%$ & & Specificity 92\% & NS & \\
\hline & Diagnostic OR 8.83 & Diagnostic OR 5.86 & Diagnostic OR 6.53 & NS & Lahaye et al (7) \\
\hline \multirow{2}{*}{$\begin{array}{l}\text { Circumferential resection } \\
\text { margins }\end{array}$} & Diagnostic OR 8.83 & Diagnostic OR 5.86 & Diagnostic OR 6.53 & NS & Lahaye et al (7) \\
\hline & Specificity NA & Specificity NA & Specificity $92 \%$ & & Mercury Study Group (13) \\
\hline
\end{tabular}

NA Not available; NS Not statistically significant

expand the role of this modality in rectal cancer staging. Indeed, EUS has been shown to be helpful in evaluating subepithelial masses and in detecting local tumour recurrence (11).

Although many studies have compared the accuracy of diagnostic imaging modalities for the staging of rectal cancer, it is difficult to draw definitive conclusions from the available literature. Manyw of the studies are small and vary in study design, patient population, imaging technique and results. Nevertheless, two recent well-conducted meta-analyses and a systematic review of the literature $(6,7,10)$ point to EUS as the imaging modality of choice for determining muscularis propria and perirectal tissue invasion, as well as nodal involvement. EUS and MRI may play complementary roles, with EUS being most accurate for early localized cancers and MRI more useful in assessing advanced cancers (10). In the situation of our patient, in which EUS and MRI reported markedly divergent clinical situations associated with differing prognostic outcomes (ie, noninvasive tumour versus invasive cancer), and given that neither imaging modality has 100\% sensitivity and specificity, the patient elected to undergo surgical resection. Similar cases will require individual decision-making regarding risk-benefit and informed consent on the part of the patient.

\section{REFERENCES}

1. Isbister WH, Fraser J. Large-bowel cancer in the young: A national survival study. Dis Colon Rectum 1990;3:363-6.

2. Jemal A, Tiwari RC, Murray T, et al. Cancer statistics, 2004. CA Cancer J Clin 2004;54:8-29.
3. Beets-Tan RG, Beets GL. Rectal cancer: Review with emphasis on MR imaging. Radiology 2004:232:335-46.

4. Sobin LH, Fleming ID. TNM Classification of Malignant Tumors, fifth edition (1997). Union Internationale Contre le Cancer and the American Joint Committee on Cancer. Cancer 1997;80:1803-4.

5. Chapuis PH, Dent OF, Fisher R, et al. A multivariate analysis of clinical and pathological variables in prognosis after resection of large bowel cancer. Br J Surg 1985;72:698-702.

6. Bipat S, Glas AS, Slors FJ, et al. Rectal cancer: Local staging and assessment of lymph node involvement with endoluminal US, CT, and MR imaging - a meta-analysis. Radiology 2004;232:773-83.

7. Lahaye MJ, Engelen SM, Nelemans PJ, et al. Imaging for predicting the risk factors - the circumferential resection margin and nodal disease - of local recurrence in rectal cancer: A meta-analysis. Semin Ultrasound CT MR 2005;26:259-68.

8. Kulinna C, Scheidler J, Strauss T, et al. Local staging of rectal cancer: Assessment with double-contrast multislice computed tomography and transrectal ultrasound. J Comput Assist Tomogr 2004:281:123-30.

9. Chun HK, Choi D, Kim MJ, et al. Preoperative staging of rectal cancer: Comparison of 3-T high-field MRI and endorectal sonography. Am J Roentgenol 2006;187:1557-62.

10. Skandarajah AR, Tjandra JJ. Preoperative loco-regional imaging in rectal cancer. ANZ J Surg 2006;76:497-504.

11. Bhutani MS. Recent developments in the role of endoscopic ultrasonography in diseases of the colon and rectum. Curr Opin Gastroenterol 2007;23:67-73.

12. Greene FL, Page DL, Fleming ID, et al, eds. AJCC Cancer Staging Manual, 6th edn. New York: Springer, 2002.

13. The Mercury Study Group. Diagnostic accuracy of preoperative magnetic resonance imaging in predicting curative resection of rectal cancer: A prospective observational study. BMJ 2006;333:779. 


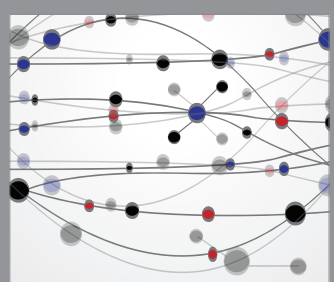

The Scientific World Journal
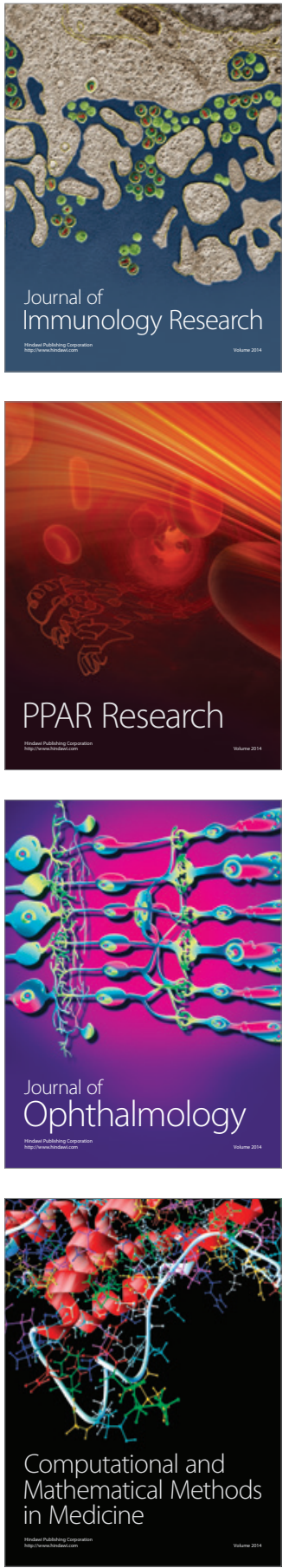

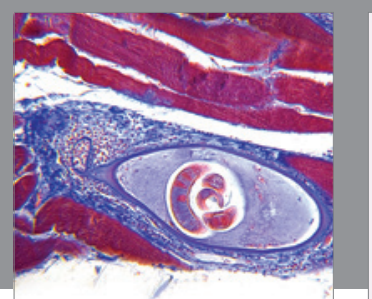

Gastroenterology Research and Practice

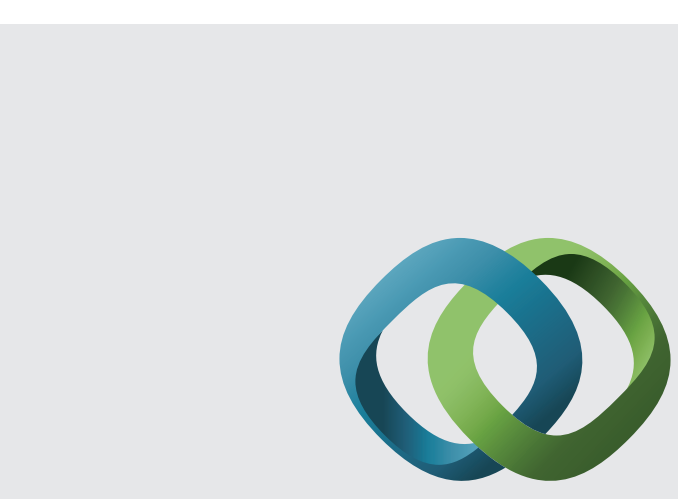

\section{Hindawi}

Submit your manuscripts at

http://www.hindawi.com
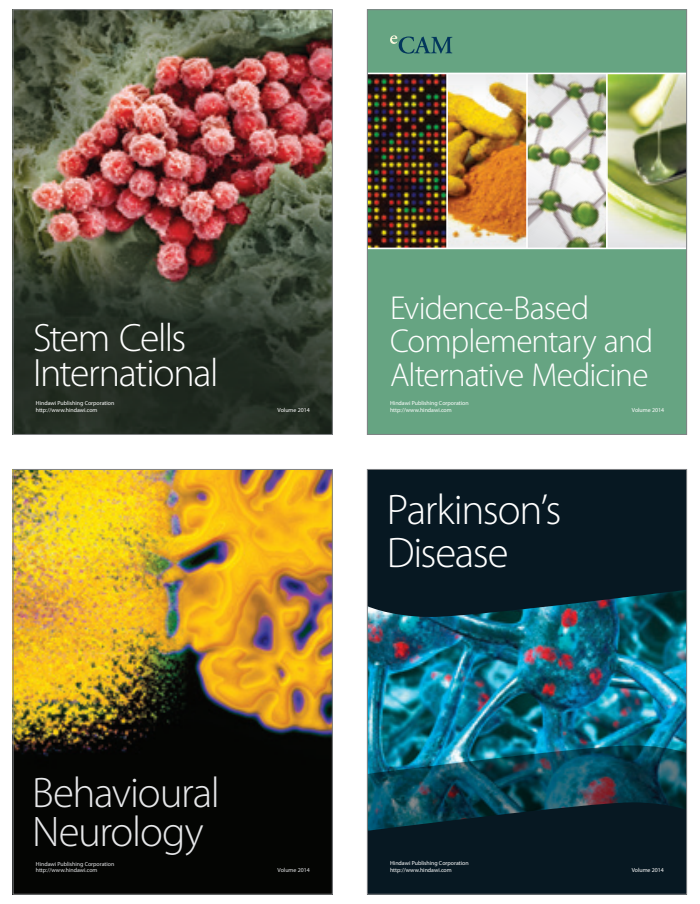
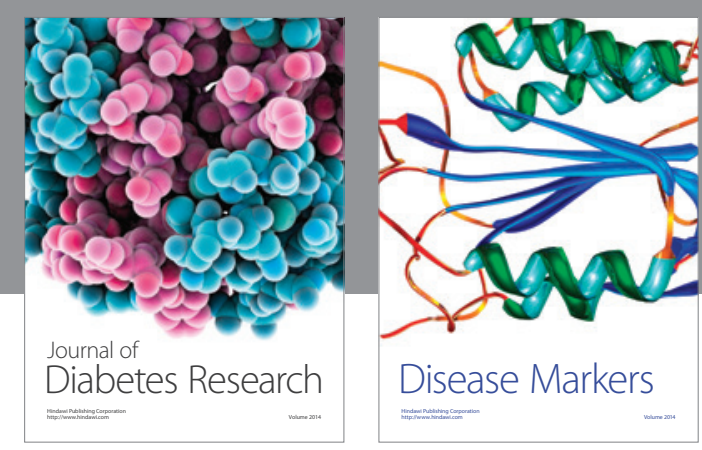

Disease Markers
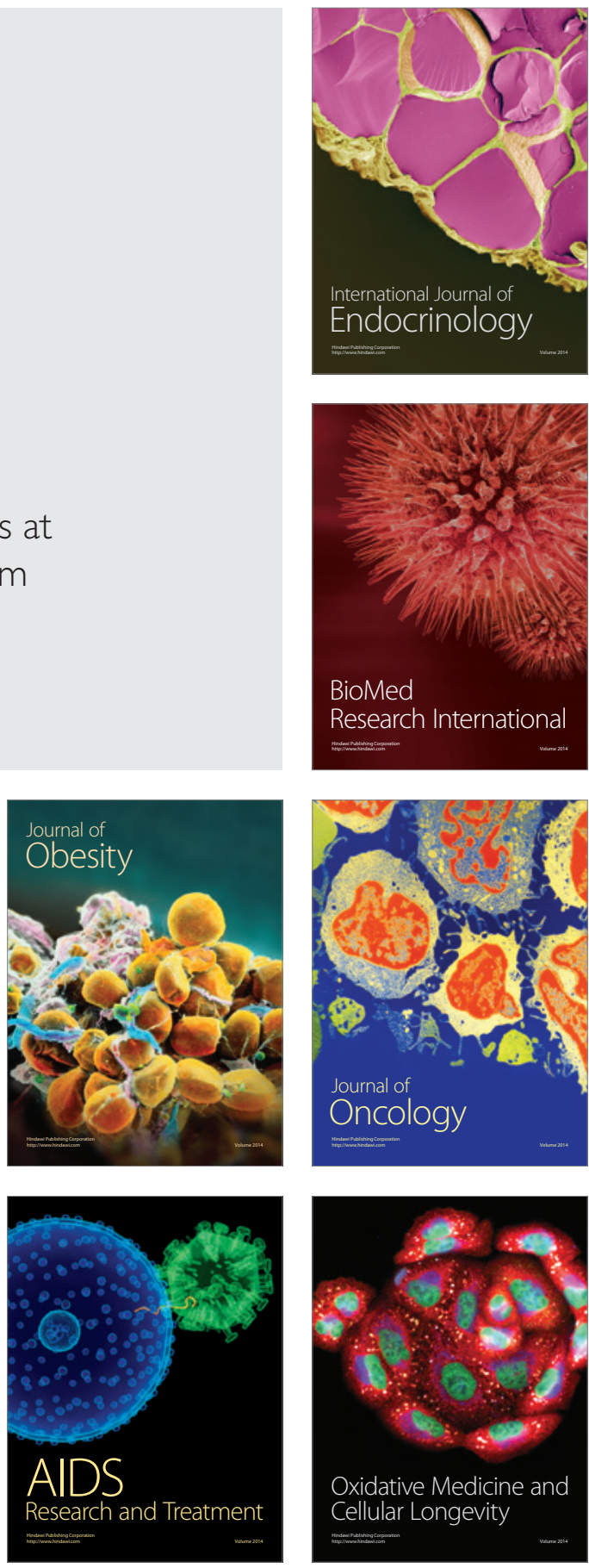